\title{
Contemporary Advanced Methods for Early Caries Detection and Diagnosis
}

\author{
Mironova $\mathbf{J}^{1}$, Gusiyska $A^{2}$, Vasileva $\mathbf{R}^{3}$, Dyulgerova $\mathbf{E}^{4}$, Gulbenkiyan $\mathbf{E}^{5}$ \\ ${ }^{1,5}$ Assistant Professor in the Department of Conservative Dentistry, Faculty of Dental Medicine, Medical University - Sofia, Bulgaria \\ ${ }^{2}$ Associate Professor in the Department of Conservative Dentistry, Faculty of Dental Medicine, Medical University - Sofia, Bulgaria \\ ${ }^{3,4}$ Professor in the Department of Conservative Dentistry, Faculty of Dental Medicine, Medical University - Sofia, Bulgaria
}

\begin{abstract}
Nowadays it is apparent that the conventional methods for early caries detection do not fulfill the criteria for the ideal clinical methods (and also to be used in scientific studies). In this regard they are subjective and insensitive. In this point it is of paramount importance to develop novel detecting techniques, which will be promising quantitative detecting methods of early caries lesions. In this assumption there are new technologies and devices for detection and diagnosis of dental lesions at their early stages of formation, evaluating their activity with higher sensitivity and specificity. Some of these devices are developed and commercially available, others are still under development. Consequently, there some creative contemporary methods and devices with great theoretical impact and exceptional practical preferences as diagnostic techniques and methods are presented: i/ the technique of optical coherence tomography (OCT), ii/ polarized Raman spectroscopy (PRS).
\end{abstract}

Keywords: caries detection, optical coherence tomography (OCT), polarized Raman spectroscopy (PRS)

\section{Introduction}

Dental caries is a dietary carbohydrate-modified bacterial infectious disease and is one of the most common bacterial infections in humans [1]. Dental caries is an irreversible, chronical disease, which initiated, progresses as a dynamic, complex, multifactorial process affecting the mineralized dental structures. It was accepted that demineralization is a result of the dissolution rate of calcium phosphates from the mineral part of the enamel, which is greater than the recombination rate in the remineralization (as a result of low ionic concentration gradient between saliva and area of demineralization). In this regard, dissolution of the mineral portion and the destruction of the organic substance of the tooth often leads to irreversible cavitation $[1,2]$.

Although, several prevention measures can be taken to reduce the occurrence of dental caries, it is still one of the most common diseases experienced by humans. Clinically, dental caries is characterized by progressive demineralization of the tooth and destruction of its organic components [3]. Moreover, new carious lesions are commonly found just below the inter-proximal contact sites(between adjacent teeth), an area that is difficult to examine. Therefore, better diagnostic tools are needed to detect early non cavitated carious lesions and to monitor their activity.

Detection and monitoring of the process of de- and remineralization by dental caries is a dentist's challenge and in spite of numerous studies with respect to caries detection, evaluating different tools, caries diagnosis continues to be a provocation task for dental practice.

As a role, detection and diagnosis of dental caries will allow to prevent the progression of the lesions and there after avert the need for invasive, irreversible removal and reconstruction of tooth structure. It is noteworthy to underline that a primary goal of contemporary dentistry is the early detection and prevention of dental caries. Detecting early dental caries lesions and monitoring the dynamic of de-/re-mineralization are great challenges in diagnostic methods relying on objective clinical criteria. The traditional methods for dental caries detection via radiographic and visual-tactile diagnostic lack sufficient sensitivity and specificity for early caries detection and do not provide information of the lesion's activity [4]. The validity of caries progression due to the assessment of de/remineralization, instead of the cavitation is the end border of failed caries prevention [5-8]. Therefore the accurate detection in the pre-cavitation stages of enamel lesion is very important for undertaking proper preventive and therapeutic procedures and avoiding unnecessary treatment. Hence early detection of dental caries and its prevention are necessary because incipient lesions are non cavitated [9-12].

Furthermore, if carious lesions are detected early enough, they can be arrested or reversed through nonsurgical therapies. The effectiveness of this nonsurgical therapy is depending on detection of the lesion in the outer enamel and requires imaging modalities that can safely and accurately monitor the success of such treatment.

\section{Shedding new light on early caries detection}

In recent years, on increased research activity regarding diagnostic methods, can be seen particularly in the assessment of active early dental lesions. Caries diagnostic methods have transformed from the conventional techniques and have evolved. Various techniques have been explored to act in accordance with the need for detection and diagnosis of caries lesions, better objective diagnostic tools with high sensitivity and specificity [13-15]. This leads to more versatile caries assessment methods that allow longitudinal follow-up of caries lesions and ability to determine changes in lesion severity in time. Caries assessment should include the monitoring changes in caries activity. 


\section{International Journal of Science and Research (IJSR) \\ ISSN (Online): 2319-7064}

Index Copernicus Value (2016): 79.57 | Impact Factor (2015): 6.391

The majority of caries assessment techniques are based on changes in the optical properties of teeth. These may be based on changes in the scattering properties of enamel. A lot new advanced systems are in their early stages of development and many of them are based solely in laboratories, but with potential to be produced as devices in the future. For that reason significant work in developing systems into clinically and commercially acceptable applications is done.

In this article, we do not review the various optical methods or devices for caries detection, as these have been precisely discussed inrecent professional literature. Our intention isto introduce two new emerging optical techniques, which might be useful in the detection of early enamel caries, and provide an overview of a contemporary research in this direction. The technique of optical coherence tomography (OCT) recently received much attention due to its capability for real time depth imaging of internal tooth structure at high spatial resolution. In addition, some technological problems must be solved in the near future to allow the use of OCT in every day practice. In the same field of new research isone other method of scientifically and practical interest - the polarized Raman spectroscopy (PRS). Raman spectroscopy for detection of early carious lesions is a subject of providing biochemical dates characterizing the apatite in dental structures, the major mineral component of tooth enamel.

\section{Polarization - sensitive Optical coherence Tomography (OCT)}

OCT is non-invasive, non destructively imaging system that can visualize the internal structures providing high resolution $(10-30 \mu \mathrm{m})$ morphologic depth images. OCT is developed on low-coherence interferometry where the light is projected overthe sample and signals intensity reveal depth-resolution information about scattering and reflection of the light in the sample [16]. The technique is based on coherent back-scattered light. Briefly, OCT system contains a Michelson interferometer that splits a light beam in two paths, bounding the beam in two mirrors (one fixed and one moving) recombining the beam into two paths. The interference pattern created by the reflection beams generates a depth profile at a single point along the laser trajectory (Fig.1,2).

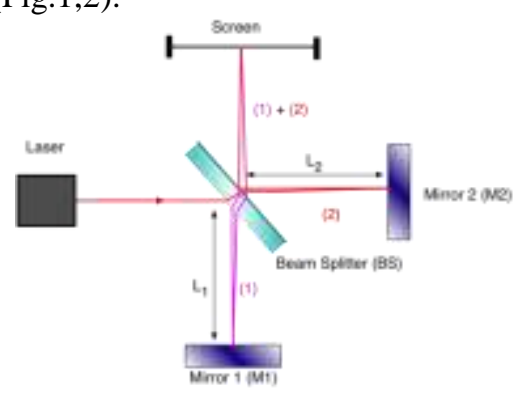

Figure 1: Schematic illustration of Michelson interferometer

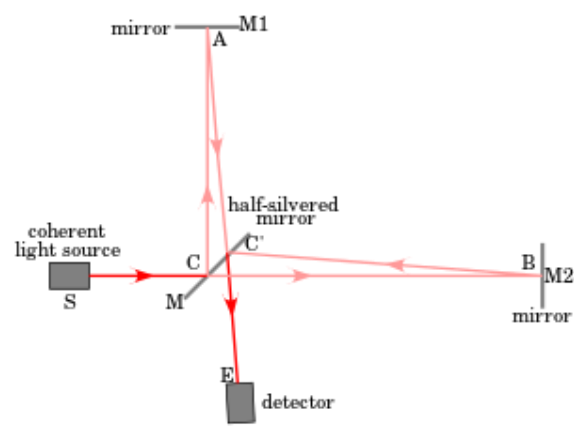

Figure 2: Path of the light.

OCT can image only the first several millimeters of tissue (2-4 $\mathrm{mm})$, depending on the wave length of the light used. Thus OCT is better suited for imaging near-surface structures. OCT light back-scattered by changing in refractive index as the light encounters different tissue types or structures. As a result analysis of images has been based on the increased signal intensity values to quantify parameters such as depth and mineral loss. Unlike the other optical techniques OCT produced images of the microstructure of tooth tissues assessed from the outer surface towers the pulp [17-19].

The technique on Optical coherent tomography (OCT) is based on back -scattering light. The light source is low coherent laser with a wave length in the near-infrared region (NIR) $(850 \mathrm{~nm}$ or $1310 \mathrm{~nm})$ which is the region of the electromagnetic spectrum just beyond the visible red portion. At the sample, the power generated is very low, about $750 \mu \mathrm{W}$ using $850 \mathrm{~nm}$ wavelength or $7 \mathrm{~mW}$ with 1310 $\mathrm{nm}$ wavelength system. Light in the near-infrared region is able to penetrate tissue better than light in visible region of the spectrum. Optical coherence tomography (OCT) is a non-ionizing tissue imaging modality based on reflectivity and phase retardation by tissue surfaces. It has been used in medicine and demonstrated a great promise in assessing early caries [20-23]. The technique, as it was said earlier in this text, is based on coherent back-scattered light changes in refractive index as the light encounters different tissue types or structures (e.g. enamel vs, dentin) and other [24,25]. OCT is a powerful technique useful for examination of tissues with multiple layers or demarcations. It has been used in medical imaging for the past 15 years. In the past decade OCT has been applied in dentistry to image soft and hard tissues of the oral cavity, with many studies that still yet at the research stage [26,27] and the technique not yet developed into commercially available dental devices.

It is known that demineralization of enamel in early dental caries and the porosity in damming zone of tooth increaseas a consequence of mineral loss in the body of the lesion[28]. In such circumstances, it is highly probable that micro interfaces between mineral crystals and water within the pore cause higher reflectivity with pore open spaces in the matrix and the scattered light penetrates deeper into the enamel destruction. The enamel surface of the incipient lesion is still intact with demineralization occurring of the subsurface.

The light scattering below the surface forms a triangular pattern. The shape is a characteristic of subsurface lesions and is supported by corresponding histologic picture.

Volume 6 Issue 12, December 2017

www.ijsr.net

Licensed Under Creative Commons Attribution CC BY 


\section{International Journal of Science and Research (IJSR) \\ ISSN (Online): 2319-7064}

Index Copernicus Value (2016): 79.57 | Impact Factor (2015): 6.391

Incipient lesions are visible on OCT images, with information available about lesion location, depth, including proximity to the dentin enamel junction and surface characteristics (intact,cavitated). In studies about dental caries in older adults, Holzmann at all [29] demonstrated thatOCT - imaging approach shows good accuracy with very good sensitivity and specificity for early caries detections. Diagnostic accuracy was extremely outstanding.

In regions of hypo-calcification OCT imaging can show increasing light back scattering at the surface, which could be misinterpreted as sign of early caries. In such falsepositive results OCT was coupledwith polarized Raman spectroscopy (PRS) to obtain biochemical information about the confirmation of caries [30]. PRS provides details on molecular composition (e.g. collagen in dentin vs. predominantly inorganic apatite in enamel) and molecular structure of cells and tissues.

In contrast to all of well-known technologies using only alteration of fluorescence, reflectance, electrical conductance, or impedance properties to monitor changes of enamel demineralization in caries is important to underline that the optical coherent tomography (OCT) can additionally produce image of tissue microstructure of caries lesion and to show the changes within. Moreover, the results can be compared quantitatively and qualitatively with histological methods such as microcomputer tomography, the current gold standard for measuring demineralization [31]. Additionally on structure image measurement, OCT is also applied for crack (fracture) and micro-leakage. Strong reflection from the material surfaces appears to be effective in conventional OCT setups for the detecting signal from the border of cavitated caries, tooth fraction, cracks and interfacial gap of restoration [32].

Since the optical characteristics of the enamel and dentin differ by structure and composition they can beseparated from each other with the dentin-enamel junction (DEJ), appearing as a dark borderline. In enamel caries the signal generally increase and the demineralized region appears brighter on grayscale ofthe OCT images[33].

Recently, OCT was also usedin pulp-dentin compleximaging [34]. The results of this study showed the capacity of OCT to distinguish pulp form dentinand can be used to predict remaining dentin thickness above the pulp, and will permit more predictive prognosis of the dental treatment.

It is important to underline that OCT is an effective diagnostic tool because it is a non-invasive, non-destructive, non-radiated, and real-time monitoring method. However, current data processing techniques are not yet versatile enough to allow this technology to be routinely used in clinical dentistry setting, but it is not unconceivable to forecast that OCT could become a routine diagnostic tool for the assessing and treatment planning of enamel defects.

Following the modification of the system to produce polarization sensitive OCT (PS-OCT), the application of OCT in dentistry has widened. Recently Amaechi and coworkersused combination of PS-OCTtechnology with confocal microscopy to further the application of the OCT into dental tissue imagining [35-37].This combination system can operate in different regimes to deliver A scans, B scans (longitudinal images), and $\mathrm{C}$ scans (en face or transverse images). The confocal image, along with en face OCT image at each depth, was useful in identifying the caries lesion and aligning the tooth. This was especially useful for the in vivo application of the system [36, 37]. It will be of interest to emphasize that factors such as straining, presence of saliva, bacteria or plaque which have been identified to adversely affect other technologies, especially based on tooth tissue fluorescence, they do not influence with OCT imaging and measurements. Furthermore, carious regions by OCT can provide more detail such as decay depth, size and boundary. For suspect regions, OCT images can verify whether the regions are carious lesions and how deep the lesions are. OCT signal have the potential in assessment of the remineralization process, and which can be specifically implemented clinically to monitor the mineralization progress of the lesion.

A tool with both high sensitivity and high specificity will be useful to assist dentists in their decision-making and treatment process. Over the past decade, many functional OCT systems with specific optical characteristics have been reported for new biomedical research applications. OCT is today one of the most rapidly developing biomedical optical modalities. Currently OCT devices for routine use and specific caries diagnostic-software tend to be too costly and remain unavailable to the best of our knowledge.

\section{Polarized Raman Spectroscopy(PRS)}

Both OCT and PRS involve non-ionizing radiation and can be used routinely to screen for early caries lesions, to monitor caries process and to assess the success of remineralization treatments. Frequent use of OCT-PRS would provide insight into caries activity. OCT imaging in regions of hypo-calcification can sometime show increased light back-scattering at the surface, which could be misinterpreted as signs of early caries. OCT could be coupled with PRS to obtain biochemical information for confirmation of caries [38-40].

Recently, the use of Raman spectroscopy for biomedical applications including dentistry has significant increased. The spectral changes are unique and specific for the given sample; hence, Raman spectroscopy has proved highly specific and sensitive compared to other spectroscopic analysis in the biomedical field. Other advantages of Raman spectroscopy are that the technique is noninvasive, nondestructive and the results obtained are reproducible and require minimal or no sample preparation. Raman spectroscopy has high biochemical/biomolecular specificity and biomolecular orientation sensitivity and has emerged as an attractive tool for biochemical characterization and diagnosis, characterization of crystal morphologiesand phase composition in early caries process $[41,42]$. Understanding the variation in hydroxyapatite crystallite of natural enameland as a result of dental caries is important not only for prevention mechanisms but also for the design of preventive agents.

\section{Volume 6 Issue 12, December 2017}




\section{International Journal of Science and Research (IJSR) \\ ISSN (Online): 2319-7064}

Index Copernicus Value (2016): 79.57 | Impact Factor (2015): 6.391

Like OCT, PRS measures light scattering. Even though, scattered photons have the same energy and wavelength as the incoming excitation light about 1 in $10^{7}$ photons scatters at an energy different from that of the incoming light. This energy difference is proportional to the vibration energy of the scattered molecules within the sample and is known as the Raman Effect (is inelastic scattering of photons by molecules). Thus, the Raman spectroscopy is a vibrational spectroscopy technique used to assess light scattered from biological molecules and ions, so that wave length difference between scattered and incident light corresponds to molecular vibration, leading to frequency shift bands (labeled in $\mathrm{cm}^{-1}$ ) in the Raman spectrum $[43,44]$.

To investigate the chemical composition of different enamel and dentin areas, Raman spectra are used, and Raman spectroscopy is one of the few methods which offered the opportunity to study enamel mineralization nondestructively in vivo. Raman spectra are obtained by excitation with $632,8 \mathrm{~nm}$ radiation from $\mathrm{He}-\mathrm{Ne}$ laser generation less than $<12 \mathrm{~mW}$ on the samples. Due to fluorescence, the samples were photo-bleached by laser for $15 \mathrm{~min}$ before spectra recording. The acquisition time was 90 s. with three accumulations. The Raman unit is also equipped with a confocal microscope with a minimal step with of $50 \mathrm{~nm}$, and an air-cooled CCD detector of 1024x256 pixels. The spectra obtained from Raman microscopy were normalized using software (system Software, Chicago, ILUSA). Vibrational spectroscopic technique such as Raman and Fourier transform infrared (FTIR) spectroscopy for analysis of biological tissues are emerging as possible alternatives to traditional diagnostic techniques [45]. Recently the use of Raman spectroscopy for dentistry has significantly increased form its high biochemical specificity, low water sensitivity and capability to work in the nearinfrared region (NIR) and to the advices in instrumentation and development of fiber optic probes $[46,47]$.

In addition, the use of Raman spectroscopy application in dentistry has significantly increased due to the fact that biological hard tissues contain a significant amount of water and water has minimal interference in Raman spectra. Besides, it validates to be rather good technique for molecular analysis of dental hard tissues and particularly dentin [48]. Examining of various intensities of $\mathrm{PO}_{4}^{3-}$ vibrations $\left(1043 \mathrm{~cm}^{-1}, 590\right.$ and $\left.431 \mathrm{~cm}^{-1}\right)$ showed a consistent change in the intensities of spectra of carious lesions compared to healthy enamel. The spectra changes are attributed to demineralization induced alteration of enamel crystallite morphology and/or orientation. Any change in the hard tissue of enamel produced by caries willresult in increasing the depolarization ratio, and bands of regions $v_{2}$, $v_{3}$, and $v_{4}$ do not exhibit significant alteration in spectra profilewith a change in orientation. On other side there are some changes in relatively intensity of the bands. The spectral changes are attributed to demineralization -induced alterations of enamel, crystallite morphology or orientation. On the other side, there are some changes in relative intensity of the bands, which can be attributed to their complex structures. The calcium apatite in dentin and email were characterized by Raman spectroscopy $[49,50]$.
In dentin spectrum, four main bands were observed, corresponding to the fundamental frequency models $v_{1}, v_{2}$ $v_{3}, v_{4}$. The sharpest and most intensive band $v_{1}$ related to the symmetrical stretching of the tetragon of oxygen atoms surrounding the phosphate atom. It has been observed that the $v_{1}$ spectral region $\left(1000-900 \mathrm{~cm}^{-1}\right)$, Raman spectra always contain detail bond peaks with a relatively narrow line width for the peaks of 968 and $951 \mathrm{~cm}^{-1}$. There were always accompanying bands in the low and higher wavenumbers which probably correspond to the $v_{2}, v_{4}$ and $v_{3}$, modes, respectively. However, these bands are weaker in intensity and maintain a relatively well-resolved band structure. These indicate the presence of crystalline phosphate -based minerals in dentin.

The stretch bands allocate in tooth structure are 965 $955 \mathrm{~cm}^{-1}$ ( $\mathrm{PO}_{4}$ from apatite), $1255-1245 \mathrm{~cm}^{-1}$ (amide III from peptide bonds), $2940 \mathrm{~cm}^{-1}, 1465-1455 \mathrm{~cm}^{-1}\left(\mathrm{CH}_{2}\right.$ wave $), 1565-$ $1555 \mathrm{~cm}^{-1}$ (amid II from peptide bonds), $2940 \mathrm{~cm}^{-1}, 1465-$ $1455 \mathrm{~cm}^{-1}(\mathrm{CH} 2), 1565-1555 \mathrm{~cm}^{-1}$ (amid II from peptide bonds), $1620-1610 \mathrm{~cm}^{-1}$ (Y8a tyrosine side chain vibration) and $1665-1655 \mathrm{~cm}^{-1}$ (amide I from peptide bond). Type I collagen I accounts for $90 \%$ of the dentin protein fraction. The four main amide bands are amid I (1700-1600 $\left.\mathrm{cm}^{-1}\right)$ amid II (1600-1500 $\left.\mathrm{cm}^{-1}\right)$ amid A (3400-3350 $\left.\mathrm{cm}^{-1}\right)$ and amid B (3085-3070 $\left.\mathrm{cm}^{-1}\right)$.

Dentin dehydration did not remove the water, strongly bound to collagen, and therefore did not affect the triple helical stricture. The amide I bands always give three peaks typical of collagen, the $1694 \mathrm{~cm}^{-1}$, component attributed to $\mathrm{C}_{3} \mathrm{O} 3 \ldots \mathrm{H}_{2} \mathrm{O}$, the $1662 \mathrm{~cm}^{-1}$ peak, attributed to $\mathrm{C}_{2} \mathrm{O}_{2} \ldots . \mathrm{H}_{4} \mathrm{~N}_{4}$ and the $1637 \mathrm{~cm}^{-1}$ peak attributed to $\mathrm{C}_{1} \mathrm{O}_{1} \ldots \mathrm{H} 2 \mathrm{O}$. Collagen mineralization is thought to begin in whole zone, and the crystals are oriented with their $\mathrm{c}$ axis parallel to the long axis of the collagen molecules. Therefore, the Raman spectrum of tooth shows prominent vibrational bands related to its composition. Some of the main Raman bands on tissues are at $\sim 575, \sim 960, \sim 1450 \mathrm{~cm}^{-1}$. The $\sim 1450 \mathrm{~cm}^{-1}$ band is attributed to amide I and amide III stretching modes as well as to the bending and stretching modes of $\mathrm{CH}$ groups of lipids and proteins; the ones at $\sim 960$ and $\sim 575 \mathrm{~cm}^{-1}$ are attributed to phosphate and fluoridated apatite, respectively. The different peaks identified in dentin spectra are mainly bands associated with inorganic components (minerals), which appeared in the spectral range approximately 959 and $1070 \mathrm{~cm}^{-1}$

Including bands $v_{1}$ phosphate $\left(\mathrm{PO}_{4}{ }^{3-}\right)$ and $\mathrm{B}$-type mineral carbonate $\left(\mathrm{CO}_{3}{ }^{2-}\right)$ and the band associated with the organic components (collagen). The organic bands appeared in the spectra range near $1,240 \mathrm{~cm}^{-1}$ for $(\mathrm{NH})$ amide III and 1,665 $\mathrm{cm}^{-1}$ for $(\mathrm{NH})$ amide I. It is possible to compared the intensities ratios between different results as described below.

\section{Carbonate to phosphate ratio}

The prominence of carbonate bond around $1070 \mathrm{~cm}^{-1}$ in the Raman spectrum shows the degree of carbonate substitution in the structure of apatite. Phosphate to $\mathrm{CH}_{2}$ ration (960 to $1450 \mathrm{~cm}^{-1}$ ) wagging, the mineral to organic ratio was calculated. Resent study on Raman spectroscopy helps in characterizing Hydroxyapatite crystals undergo dissolution 


\section{International Journal of Science and Research (IJSR) \\ ISSN (Online): 2319-7064}

Index Copernicus Value (2016): 79.57 | Impact Factor (2015): 6.391

in acidic $\mathrm{pH}$, and phosphate ions $\left(\mathrm{PO}_{4}{ }^{3-}\right)$ and hydroxyl ions $\left(\mathrm{OH}^{-}\right)$in the tooth -biofilm interface and form of $\mathrm{H}_{2} \mathrm{PO}_{4}{ }^{-3}$. The $\left(\mathrm{PO}_{4}{ }^{3-}\right)$ forms dissolved crystals and shows several increased Raman peaks at 1043,590, and $431 \mathrm{~cm}^{-1}$ (Fig.3,4,5) [51,52].

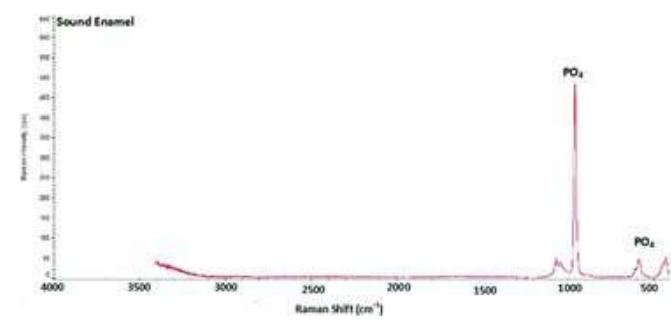

Figure 3: Raman spectroscopy of sound enamel.

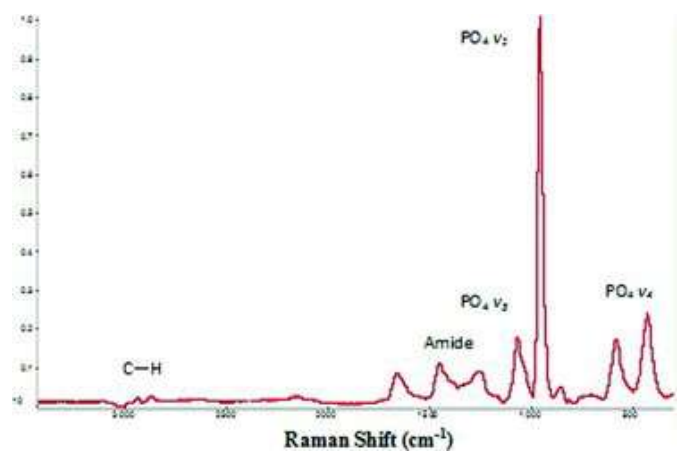

Figure 4: Raman spectroscopy of sound dentin.

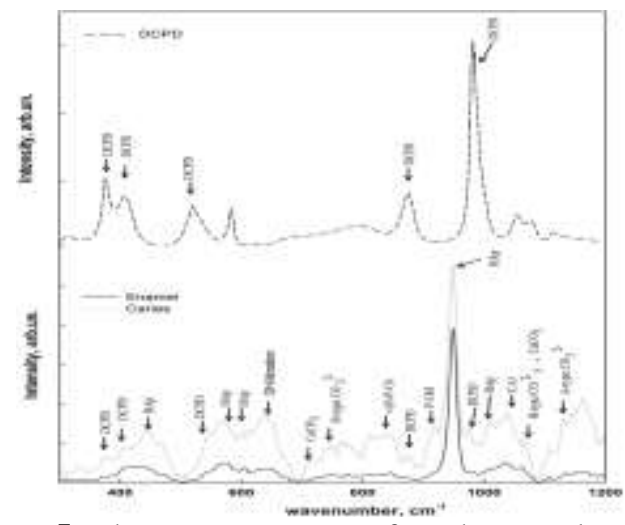

Figure 5: The Raman spectra of tooth enamel. DCPD

Raman Spectra-on top; sound and carious enamel - at the bottom.

Recent studies of Raman spectroscopy have shown promising results in diagnosing early dental caries. As stated previously dental caries is characterized by demineralization of inorganic substanceand destruction of organic matrix. Moreover, Raman spectroscopy is recommended as an effective and relatively easy tool for early caries diagnosis because during the caries process the inorganic matter of tooth is gradually replaced by organic matter, which shows strong organic peaks than normally seen [52]. PSR helps in characterization of apatite crystals undergo dissolution in acidic $\mathrm{pH}$, react with $\mathrm{H}^{+}$and the $\left(\mathrm{PO}_{4}{ }^{3-}\right)$ forms dissolved crystals, which shows several increased Raman peaks at 1043,590 , and $431 \mathrm{~cm}^{-1}$.

Reduced Raman polarization anisotropy was demonstrated at $959 \mathrm{~cm}^{-1}$, which refers to phosphate ions within the hydroxyapatite crystals. Such results showed sensitivity of $97 \%$ and specificity $100 \%$.

PRS can provide information about the primary matrix and thus the state of demineralization or remineralization of the tooth. It can also provide information about the composition, the crystallinity, the orientation of the mineral crystals in matrix, all of which are affected in caries formation or in the process of remineralization. Studies generally are focused on the phosphate peak from carbonate hydroxyapatite and how biochemically is affected by de- and remineralization. Nowadays this studies are used ininvestigation only in ex vivo experiments by measurements on sound and carious enamel and was found high sensitivity of $100 \%$ and specificity $98 \%$ [53]. The early changes in the spectrum are mainly due to both the de- and remineralization of the tooth hard tissues and the change in the mineral component. Raman spectroscopy is one of the few methods which offer the opportunity to study enamel mineralization nondestructively in vivo.

Raman spectroscopy will not only be used in diagnosing dental caries. In addition, other development defects of affecting enamel, dentin and bone that have reduced mineral content can also be diagnosed [54]. Among the disorders affecting the teeth, is amelogenesis imperfecta which is rare developed disorder affecting enamel, subject of Raman spectroscopy. It is characterized by hypo mineralization or hypoplasia, biochemical changes and early diagnosis of these genetic disorders will notonly help dentist to take measures to restore teeth but will help to diagnosis other defects affecting the body [55].

Preliminary studies have also shown that both OCT and PRS can be used to follow de- and remineralization longitudinally using quantitative parameters [56-58].

In addition, like OCO, PRS measures light scattering and as with other emerging optical methods, the properties of the scattering light within sound and carious regions are explored to determine their use in caries detection $[59,60]$.

Both OCT and PRS involve non-ionizing radiation and therefore, can be used routinely to screen for early lesions, to monitor the caries process, to assess the success of remineralization treatment and to educate and motivate patients. Frequent use of OCT-PRS to collect data from caries sites longitudinally would provide insight into caries activity. A tool with both high sensitivity of high specificity will be useful supplement to assist dentists in their decision -making and treatment planning processes. Unfortunately, OCT and PRS, do not have commercial realization with scientific validation yet [61].

In assumption, it should be seed thatsince the early diagnosis of caries is directly related to the identification of changes in inorganic components of the tooth, Raman spectroscopy was more sensitive to variations of these components. The wide field Raman imagining can discriminate sound enamel from lesion in teeth based on the contract of the mineral Raman signal distribution. At that point, the wide - field Raman imaging is a promising method in early dental caries detection and can be applied to cheek suspected locations.

Volume 6 Issue 12, December 2017 


\section{International Journal of Science and Research (IJSR) \\ ISSN (Online): 2319-7064 \\ Index Copernicus Value (2016): 79.57 | Impact Factor (2015): 6.391}

Moreover, Raman spectroscopy will be used in diagnosis of genetic disorders in development defects affecting enamel, dentin and bone.

\section{Conclusion}

A range of new quantitative and qualitative caries detection systems have been presented and discussed in this review. It was demonstrated that in recent years, methods for detection of early caries lesions have evolved considerably in controlling the demineralization process and destruction of hard dental tissues. It is well known that a lot of known diagnostic modality studding demineralization and chemical transformation in caries processes make unlikely that anyone will have adequate sensitivity and specificity of detection early caries lesions. Hence, methods presented here are advanced for detection and diagnosis demineralization and chemical transformation in mineralized dental strictures and in early caries processesand have the possibility to give qualitative and quantitative data, to be controlled at the initial phase of dental molecular destruction.

In this regard, OCT is a promising imaging modality to noninvasively visualize dental caries, tooth structures and interfacial gaps in restorations, without radiations. OCT can be safer alternative of X-ray radiography. Both OCT and PRS involve non-ionizing radiation and can be used routinely to screen early caries lesions, to monitor caries process and to assess the success of remineralization treatments. Moreover, PRS is beyond the scope of dental caries problems. In this viewpoint, it is relevant to know that PRS can be valuable diagnostic aid in studying not only the composition of dental enamel and dentin but in osteomyelitis which can be seen in the oral region involving maxilla and mandible. There is also a hypothesis that bone composition measurements by PRS would serve in the characterization of early pathophysiology of diabetic osteomyelitis .

\section{Aknowledgements}

This work was financially supported by the Bulgarian Ministry of Education and Science under Project DFNI 025/2014.

\section{References}

[1] Pitts, N. B. Modern concepts of caries measurement. J Dent Res 2004, 83 Spec C, C43-7.

[2] Featherstone, J. D. The caries balance; the basis for caries management by risk assessment. Oral health and preventive dentistry, 2004, 2 suppl., 1, 259-264.

[3] Shafer, Hine and Levy. Dental caries. - In: Textbook of Oral Pathology. Sivapathasundaram, B. and A. R. Raghu. Eds. Elsevier: New Delhi, 2006, 567-557.

[4] Meyer-Lueckel, H., S. Paris, S. Effenberger et al. Caries Management - Science and Clinical Practice. Stuttgart: Thieme Medical Publishers, 2013.

[5] Kidd, E., O. Fejerskov. Changing concepts in cariology: forty years on. Dental update, 2013, 40: 277-8, 80-2, 85-6.

[6] Kidd, E. The implications of the new paradigm of dental caries. J Dent., 2011, 39, Suppl 2: S3-8.
[7] Ekstrand, K. R., M. E. Christiansen. Outcomes of a nonoperative caries treatment programme for children and adolescents. Caries Res., 2005, 39: 455-67.

[8] Pitts, N. B., J. W.Stamm. International Consensus Workshop on Caries Clinical Trials (ICW-CCT ) - final consensus statements: agreeing where the evidence leads. J Dent Res., 2004, 83 Spec C: C125-8.

[9] Pretty, I. A., R. P. Ellwood. The caries continuum: opportunities to detect, treat and monitor the remineralization of early caries lesions. JDent., 2013, 41: S12-21.

[10] Singh, M., A. Papas, W. Vollmer, J. Bader, R. Laws, G. Maupome et al. Predictors of coronal caries progression in adults: results from theprevention of adult caries study. Community Dent Oral., 2013, 41: 558-64.

[11]Pitts, N. B., K. R. Ekstrand. ICDAS Foundation. International Caries Detection and Assessment System (ICDAS) and its InternationalCaries Classification and Management System (ICCMS) - methods for staging of the caries process and enabling dentists to manage caries. Community Dent Oral., 2013, 41: e41-52.

[12] Gomez, J., M. Tellez, I. A. Pretty, R. P. Ellwood and A. I. Ismail. Non-cavitated carious lesions detection methods: A systematic review. Community Dent. Oral Epidemiol., 2013, 41: 55-73.

[13] Lussi, A., R. Hibst, R. Paulus. DIAGNOdent: an optical method for caries detection. J Dent Res, 2004, 83 Spec C: $\mathrm{C} 80-3$.

[14] Pretty, I. A., G. Maupomy. A closer look at diagnosis in clinical dental practice: part 5. Emerging technologies for caries detection and diagnosis. J Can Dent Assoc., 2004, 70, 8: 540.

[15] Pretty, I. A. Caries detection and diagnosis: novel technologies. J Dent., 2006, 34, 10:727-39.

[16] Torres, M. G. et al. Assessment of enamel-dentin caries lesions detection using bitewing PSP digital images. J. Appl. Oral Sci., 2011, 19, 5: 62-468.

[17] Hsieh, Y. S., Y. C. Ho, S. Y. Lee, C. C. Chuang, J. C. Tsai, K. F. Lin et al. Dental optical coherence tomography. Sensors-Basel, 2013,13: 8928-49.

[18] Fried, W. A., D. Fried, K. H. Chan, C. L. Darling. High contrast reflectance imaging of simulated lesions on tooth occlusal surfaces at near-IR wavelengths. Laser Surg Med., 2013, 45: 533-41.

[19] Holtzman, J. S., K. Osann, J. Pharar, K. Lee, Y. C. Ahn, T. Tucker et al. Ability of optical coherence tomography to detect caries beneath commonly used dental sealants. Laser Surg Med., 2010, 42: 752-9.

[20]Le, M. H., C. L. Darling, D. Fried. Automated analysis of lesion depth and integrated reflectivity in PS-OCT scans of tooth demineralization. Lasers Surg Med., 2010, 42, 1: 62-68.

[21] Louie, T., C. Lee, D. Hsu, K. Hirasuna, S. Manesh, M. Staninec, C. L. Darling, D. Fried. Clinical assessment of early tooth demineralization using polarization sensitive optical coherence tomography. Lasers Surg Med., 2010, 42, 10: 738-745.

[22]Le, M. H., C. L. Darling, D. Fried. Automated analysis of lesion depth and integrated reflectivity in PS-OCT scans of tooth demineralization. Polarization sensitive optical coherence tomography. Lasers Surg Med., 2010, 42, 10: 738-745.

Volume 6 Issue 12, December 2017 


\section{International Journal of Science and Research (IJSR) \\ ISSN (Online): 2319-7064}

Index Copernicus Value (2016): 79.57 | Impact Factor (2015): 6.391

[23] Ibusuki, T., Y. Kitasako, A. Sadr, Y. Shimada, Y. Sumi, J. Tagami. Observation of white spot lesions using swept source optical coherence tomography (SS-OCT): In vitro and in vivo study. Dent Mater J., 2015, 34, 4: 545-552.

[24] Wang, X. J., T. E. Milner, J. F. de Boer, Y. Zhang, D. H. Pashley, J. S. Nelson. Characterization of dentin and enamel by use of optical coherence tomography. Appl Opt., 1999, 38, 10: 2092-6.

[25] Feldchtein, F. I., G. V. Gelikonov, V. M. Gelikonov, R. R. Iksanov, R. V. Kuranov, A. M. Sergeev, et al. In vivo OCT imaging of hard and soft tissue of the oral cavity. J. Opt Express, 1998, 3, 6: 239-50.

[26] Amaechi, B. T., S. M. Higham, A. G. Podoleanu, J. A. Rogers, D. A. Jackson. Use of optical coherence tomography for assessment of dental caries: quantitative procedure. J Oral Rehabil ., 2001, 28, 12: 1092-3.

[27] Jones, R. S., D. Fried. Remineralization of enamel caries can decrease optical reflectivity. J Dent Res., 2006, 85, 9: 804-8.

[28] Hariri, I., A. Sadr, S. Nakashima, Y. Shimada, J. Tagami, Y. Sumi. Estimation of the enamel and dentin mineral content from the refractive index. Caries Res., 2013, 47, 1: 18-26.

[29] Holtzman, J. S., D. Kohanchi, J. Biren-Fetz, M. Fontana et al. Detection and Proportion of Very Early Dental Caries in Independent Living Older Adults. Lasers in Surgery and Medicine, 2015, 47: 683-688.

[30] Choo-Smith, L.P., C. C. S. Dong, B. Cleghorn, M. Hewko. Shedding New Light on Early Caries Detection. J Can Dent Assoc., 2008, 74, 10: 913-918.

[31] Amaechi, B. T., A. G. Podoleanu, G. Komarov, S. M. Higham and D. A. Jackson. Optical coherent tomography for dental caries detection and analysis. Proc. SPIE, 2002, 4610, 100.

[32] Shimada, Y., A. Sadr, Y. Sumi, J. Tagami. Application of Optical Coherence Tomography (OCT) for Diagnosis of Caries, Cracks, and Defects of restorations. Curr Oral Health Rep., 2015, 2, 2: 73-80.

[33] Shimada, Y., H. Nakagawa, A. Sadr, I. Wada, M. Nakajima, T. Nikaido et al. Noninvasive cross-sectional imaging of proximal caries using swept-source optical coherence tomography (SS-OCT) in vivo. J Biophotonics., 2014, 7, 7: 506-13.

[34] Baz, A. K., B. B. Kyotoku, A. S. Gomes. In vitro tromographicimige of hman pulp-dentin complex. Optical coherence tomography and histology. J.Endod., 2009, 35, 1218-1221.

[35] Amaechi, B. T., A. G. Podoleanu, G. Komarov, S. M. Higham and D. A. Jackson. - In: Computer Methods in Biomechanics and Biomedical Engineering - 4. Ed. J. Middleton, N. G. Shrive and M. L. Jones. University of Wales Press, Cardiff, 2002, 3, 20.

[36] Amaechi, B. T. and A. Podoleanu. J. Biomed. Opt., 2003, 8, 642.

[37] Amaechi, B. T. and A. Podoleanu. Laser Phys., 2003, 13, 703.

[38] Choo-Smith, L. P., K. Gibrayel, C. C. Dong, D. Popescu, M. G. Sowa, B. Cleghorn. Monitoring remineralization in an artificial caries model using Raman spectroscopy and OCT: a pilot study. Caries Res., 2007, 41, 4: 326.
[39]Dong, C. C., A. Huminicki, M. G. Sowa, B. Cleghorn, L. P. Choo-Smith. Raman spectroscopic measurements of stained enamel, unstained enamel and white spot lesions. Caries Res., 2008, 42, 3: 213-4.

[40] Choo-Smith, L. P., A. Huminicki, C. C. Dong, M. Hewko, B. Cleghorn, M. G. Sowa. Investigating regions of enamel hypocalcification using optical coherence tomography and polarized Raman spectroscopy. Caries Res., 2008, 2, 3: 214.

[41] Wang, Zi, Wei Zheng, Stephen Chin-YingHsu and Zhiwei Huang. Optical diagnosis and characterization of dental caries with polarization-resolved hyperspectral stimulated Raman scattering microscopy. Biomedical Optics Express, 2016, 7, 4: 1284-1293.

[42] Ko, A. C., L. P. Choo-Smith, M. Hewko, M. G. Sowa, C. C. S. Dong and B. Cleghorn. Detection of early dental caries using polarized Raman spectroscopy. Opt. Express, 2006, 14, 1: 203-215.

[43] Kinoshita, H., N. Miyoshi, Y. Fukunaga, T. Ogawa, T. Ogasawara, K. Sano. Functional mapping of carious enamel in human Raman spectroscopy. J Raman Spectrosc., 2008, 39: 655-660.

[44] Morris, M. D., S. M. Gurjit. Raman assessment of bone quality. ClinOrthopRelat Res., 2010, 38: 1607-1617.

[45] Movasaghi, Z., S. Rehman and I. U. Rehman. Fourier transform infrared (FTIR) spectroscopy of biological tissues. Appl. Spectros. Rev., 2008, 43: 134-179.

[46] Miyazaki, M., H. Onose and B. K. Moore. Analysis of the dentin - resin interface by use of laser Raman spectroscopy. Dent. Mater., 2002,18: 576-580.

[47] Ko, A. C. T., L. P. Choo-Smith, M. Hewko and M. G. Sowa. Detection of early dental caries using polarized Raman spectroscopy. Optic. Express, 2006, 14, 1: 203 215.

[48] Tramini, P., B. Bonnet, R. Sabatier and L. Maury. A method of age estimation using Raman microspectrometry imaging of the human dentin. Forensic Sci. Int., 2001, 118: 1-9.

[49] Kirchner, M. T., H. G. M. Edwards, D. Lucy and A. M. Pollard. Ancient and modern specimens of human teeth: A Fourier transform Raman spectroscopic study. J. Raman Sectors., 1997, 28: 171-178.

[50] Boskey, A. L. and R. Mendelsohn. Infrared spectroscopic characterization of mineralized tissue. Vib. Spectros., 2005, 38: 107-114.

[51] Ionita, I. Early diagnosis of tooth decay using fluorescence and polarized Raman spectroscopy. Optoelectron. Adv. Mater., 2009, 3, 10: 1122-1126.

[52] Ravikumar R., G. Rehman, S. Basavarajappa, A. Abdullah et al. Applications of Raman Spectroscopy in Dentistry: Analysis of Tooth Structure. Applied Spectroscopy Reviews, 2015, 50: 332-350.

[53] Ko, A. C., M. Hewko, M. G. Sowa, C. C. Dong, B. Cleghorn, L. P. Choo-Smith. Early dental caries detection using a fibre-optic coupled polarizationresolved Raman spectroscopic system. Opt Express, 2008, 16, 9: 6274-84 [PubMed: 18545331].

[54] Crawford, P. J. M., M. Aldred and A. Bloch-Zupan. Amelogenesis imperfect. Journal of Rare Diseases, 2007, 2: 17. doi:10.1186/1750-1172-2-17.

[55] Renugopalakrishnan, V., R. Garduno-Juarez, J. C. H. Guerrero, P. N. C. Lavin and K. langovan. An integrated, holistic experimental and theoretical 


\section{International Journal of Science and Research (IJSR) \\ ISSN (Online): 2319-7064}

Index Copernicus Value (2016): 79.57 | Impact Factor (2015): 6.391

approach applied to the derivation of the $3 \mathrm{D}$ structure of bovine amelogenin implicated in amelogenesis imperfecta, a molecular disease characterized by a single point mutation. Rev. Soc. Quim. Mex., 1999, 43, 1: 24-29.

[56] Dong, C. C., A. Huminicki, M. G. Sowa, B. Cleghorn, L. P. Choo-Smith. Raman spectroscopic measurements of stained enamel, nstained enamel and white spot lesions. Caries Res., 2008, 42, 3: 213-214.

[57] Huminicki, A., C. C. Dong, B. Cleghorn, L. P. ChooSmith. Does calculus confound PRS and OCT detection of early caries? J Dent Res., 2008, 87 (Spec Iss B): 521.

[58] Choo-Smith, L. P., A. Huminicki, C. C. Dong, M. Hewko, B. Cleghorn, M. G. Sowa. Investigating regions of enamel hypocalcification using optical coherence tomography and polarized. Raman spectroscopy. Caries Res, 2008, 42, 3: 214.

[59] Ko, A. C., L. P. Choo-Smith, M. Hewko, M. G. Sowa, C. C. Dong, B. Cleghorn. Detection of early dental caries using polarized Raman spectroscopy. Opt Express, 2006, 14, 1: 203-15.

[60] Ko, A. C., M. Hewko, M. G. Sowa, C. C. Dong, B. Cleghorn, L. P. Choo-Smith. Early dental caries detection using a fibre-optic coupled polarizationresolved Raman spectroscopic system. Opt Express, 2008, 16, 9: 6274-84.

[61] Mohanty, B., D. Dadlani, D. Mahoney, A. B. Mann. Characterizing and identifying incipient carious lesions in dental enamel using micro-Raman spectroscopy. Caries Res, 2013, 47: 27-33. 